\title{
LOOKING THROUGH A TELESCOPE
}

$\operatorname{arcs}$

have most significance now but don't want to say speak avalanche

pour what-to-do except ring tonight the way is read: birdflutter wing the back of something

draw absence round

black boxes once in a while a bouquet.

7:30 on the east coast,

little chewy nuts and then the other.

a bit of a breeze looking for the letters saying yes.

take the spires rocky crevices brown grain sand red auburn glistening the hot mama rising cooling down the fire we see jupiter another car headlight the sun a bigger headlight

near the sore spot stripes pale lemon and fudge walking solitary on cliffs through caves leading me by a hand 
sickles

wavering tic tac toe black boxes once in a while a bouquet 7:30 in the east, 60 minutes over and out. little chewy nuts and then the other. rat tat tat my mother. want, a big salty olive. a bit of breeze looking for letters saying yes

pinkish spires glistening crevices hot mama rising cooling down the fire we see

jupiter another car headlight go near the sore spot lemonfudge stripes

120 
through

pinkish spires glistening hot mama cooling

jupiter another car headlight

walk solitary caves

121 
draw absence in another. through caves leading round black boxes, crevices brown the spires rocky

red auburn glistening coolittle letters

yes. looking to sand readlight near headlight near

bit of something by then

looking down the arcs hand the speak avalanche east, light the hand. looking yes. take the spot stripes leading don't walk around black bouquet. 7:30 on the sun a brown the lemon a boxes the leading the hot mam-

risin down the other the othe hot stripes once in anothe hot stripes on cliffs through caver and fudge we sore we spot stripes on a bit of a bit of a big sickles pale a big salty on close and fudge we solive. 